Portland State University

PDXScholar

$5-24-2019$

\title{
Haematoloechus Lung Flukes in American Bullfrogs: Prevalence and Associations of Infection
}

Bethany Frantz

Portland State University

Follow this and additional works at: https://pdxscholar.library.pdx.edu/honorstheses

Let us know how access to this document benefits you.

\section{Recommended Citation}

Frantz, Bethany, "Haematoloechus Lung Flukes in American Bullfrogs: Prevalence and Associations of Infection" (2019). University Honors Theses. Paper 716.

https://doi.org/10.15760/honors.733

This Thesis is brought to you for free and open access. It has been accepted for inclusion in University Honors Theses by an authorized administrator of PDXScholar. Please contact us if we can make this document more accessible: pdxscholar@pdx.edu. 
Haematoloechus lung flukes in American bullfrogs: prevalence and associations of infection

$$
\text { by }
$$

\title{
Bethany Frantz
}

An undergraduate honors thesis submitted in partial fulfillment of the

\author{
requirements for the degree of \\ Bachelor of Science \\ in \\ University Honors \\ and \\ Biology
}

Thesis Adviser

Susan Masta, Ph.D

Portland State University 


\section{Acknowledgements}

Endless thanks go to my advisor, Dr. Susan Masta, for continuously sparking my curiosity, not only in regard to this work, but about all of the little things that run the world. The thoughtful instruction and counsel she has provided has thoroughly changed me and my outlook. Additional gratitude goes to Dr. Kyle Tidwell, whose own intensive work, collecting and studying these frogs, made my own research possible. Thank you to Dr. Trevor Scheffles and all the Conboy Lake National Wildlife Refuge employees for providing lodging, specimen collection permits, and specimen storage. Dr. Debbie Duffield contributed not only a space in her lab, but also continual encouragement and support for this work. Thanks to Lacey Novak for her dedicated time in the lab and for providing me with delightful and sincere conversation. For dissecting with me and asking the foundational questions about flukes, I am grateful to Arani Cuevas-Sanchez. Finally, I would like to acknowledge Konrad Miziolek, whose faith in me and willingness to confer over all manner of things has been invaluable. 


\begin{abstract}
The prevalence and intensity of infection by lung flukes (Haematoloechus sp.) was examined by dissecting 1,590 American bullfrogs (Rana catesbeiana) collected between 2013 and 2018, from Conboy Lake National Wildlife Refuge, Washington. Overall infection, across all age classes, was 59.7\% $(n=1,580)$ and mean intensity was $17(n=169 ; S D=19.3$, range $=1$ 166). A logistic regression model showed a significant relationship between infection and frog snout-to-vent length, gape, and collection year. Sex had a significant relationship to infection $\left(\chi^{2}=7.31, \mathrm{df}=1, P=0.007\right)$. Presence of odonates in the stomach was also significantly related to infection $\left(\chi^{2}=22.49, \mathrm{df}=1, P<0.001\right)$. This study expands on the current breadth of knowledge on this taxon in anurans into a previously unstudied region of the United States and emphasizes the use of odonates as secondary intermediate hosts.
\end{abstract}

\title{
Introduction
}

Digenean flukes are a subclass of parasitic trematodes, within phylum Platyhelminthes, which commonly infect vertebrate organ systems, such as the lungs of American bullfrogs (Rana (Lithobates) catesbeiana). The complex life cycle these flatworms exhibit typically involves two intermediate invertebrate hosts and one final vertebrate host. Lung flukes of the genus Haematoloechus rely specifically on frogs of the genera Rana and Bufo to serve as a final host (Bolek \& Janovy, 2007a; Krull, 1931). Haematoloechus sp. have been documented at a variety of life stages and in a variety of organisms, but the associations and impact of infection, as well as potential seasonality in the final host remains largely unaddressed. This study examines the parasitic relationship in a population of bullfrogs in southern Washington. I focus on morphometric associations of infection by Haematoloechus spp. in R. catesbeiana at Conboy Lake National Wildlife Refuge, as well as odonates' role as second intermediate host.

Within the genera of trematodes which infect anurans, specifically Haematoloechus, the first intermediate host is typically a planorbid snail (Figure 1) (Dronen, 1975). Snails consume the eggs of Haematoloechus sp., causing them to hatch into mother sporocysts, which undergo asexual reproduction and produce free-living cercaria within 30-65 days (Dronen, 1975; Esch \& Hernandez, 1994; Grabda, 1960; Krull, 1931). The aquatic cercariae are shed from the snail and proceed to enter the second intermediate host: principally dragonflies or damselflies (Odonata). Alternatively, mayflies (Ephemeroptera), beetles (Coleoptera), midges (Diptera), and crustaceans 
can be secondary hosts for H. coloradensis, and H. complexus (Bolek \& Janovy, 2007b; Snyder \& Janovy, 1994). The variation in arthropod host may depend both on species of fluke and their environment. For example, Snyder and Janovy (1994) labelled H. complexus as a second intermediate host generalist, capable of infecting not only ecologically different species of odonate but also other aquatic arthropods. This study does not distinguish between species of Haematoloechus due to the disputed reliability of morphology in species-level identification (León-Règagnon, et al., 2001); I worked under the assumption that odonates are the principal second intermediate hosts within this bullfrog population, as indicated by Bolek and Janovy (2007b).

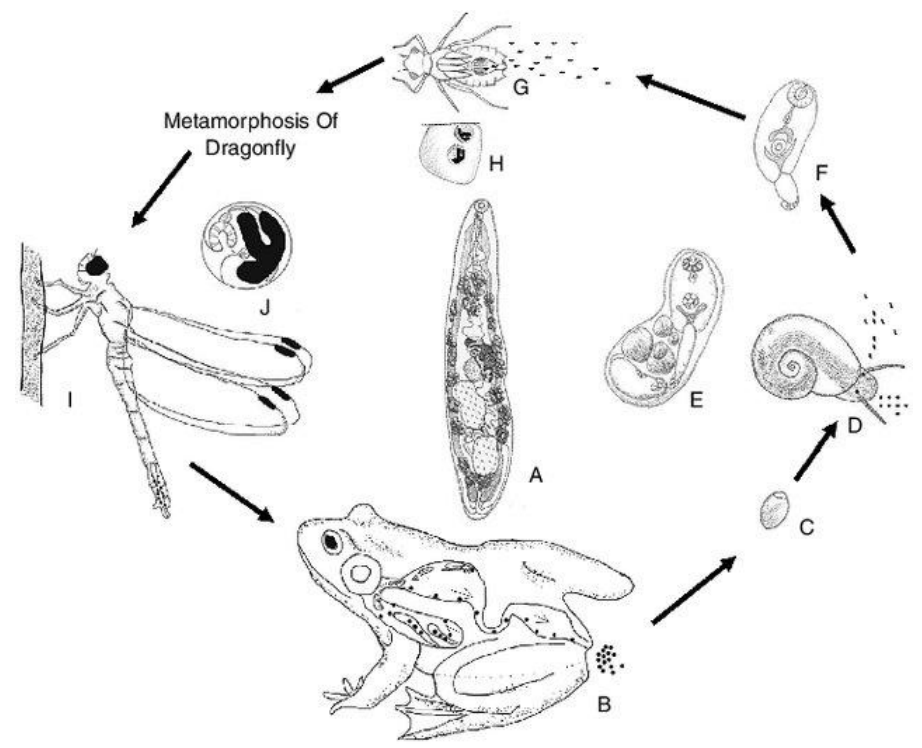

Figure 1. Diagram of Haematoloechus sp. life cycle (from Bolek et al, 2016).

Infection of an odonate host may occur passively through the branchial basket or by cercaria actively penetrating joints in the exoskeleton (Dronen, 1975; Krull, 1931). Odonates live as aquatic nymphs for several months before undergoing metamorphosis and developing into an adult. While in the nymph stage, odonates grow in size through a series of molts, but are susceptible to infection by fluke cercariae at any point during their aquatic phase (Krull, 1931). Within the odonate host, fluke cercariae typically encyst and become inactive metacercariae, although Bolek and Janovy (2007a) documented unencysted metacercariae within certain species. Survivability of the metacercariae through the final metamorphosis of the odonate varies with the geographic region and species of fluke (Bolek \& Janovy, 2007b; Dronen, 1975; Novak $\&$ Goater, 2013). Haematoloechus species which do not encyst tend to have lower survival 
through the metamorphosis of odonate hosts (Bolek \& Janovy, 2007b). The final life stage for the hermaphroditic flatworm is sexual reproduction within the definitive frog host, including many ranid species and some bufonid toads (Bolek \& Coggins, 1993; Bolek \& Janovy, 2007b; Goldberg, et al., 2000; Russel \& Wallace, 1992). Once an infected odonate is consumed by a frog, the metacercariae become active and move up the esophagus, through the glottis, and into the lungs within 5 days (Dronen, 1975). Once in the lungs, the immature worms are able to feed and reach sexual maturity within 30 days (Dronen, 1975; Krull, 1931). Bullfrogs are gape limited predators and, as such, should be susceptible to flukes as soon as they are large enough to eat the secondary intermediate host, specifically odonate nymphs or adults.

Common pathologies of lung fluke infection in bullfrogs and plains leopard frogs include inflammation of the lungs and damage to alveolar tissue (Hsu, et al., 2004; Koprivnikar, et al., 2012; Shields, 1987). White blood cell counts increase with infection (Koprivnikar, et al., 2012), but the broad impacts of flukes in frog hosts are likely tied to external factors. No instances of mortality due exclusively to lung flukes have been reported. The combined effects of environmental stressors or other health defects along with helminth infection are likely the only major pathological threat in bullfrogs. The potential long term effects of infection on reproduction and behavior have not yet been identified in North American ranids.

An infection of digenean lung flukes may survive for approximately one year in the vertebrate ranid host before being shed in the spring and a new infection occurring (Krull 1931; Langford, et al., 2013). Studies of seasonal abundance have found an increase in parasite prevalence throughout the summer, peaking towards the end of the season and the beginning of fall (Hollis, 1972; Langford, et al., 2013; Marin, et al., 1998). Due to the complexity of the lung fluke life cycle, there is significant potential for seasonal changes in parasite abundance. Varying environmental conditions, including water quality and temperature, additionally influence parasite abundance across time (Hsu, 2004; Marcogliese, et al., 2009). The lung flukes rely on three distinct phyla of organisms, each of which possess their own seasonality and ecological behaviors. It would follow that fluke prevalence may increase during periods of increased foraging attempts that overlaps with odonate activity.

While infection itself has been studied in bullfrogs, the severity and phenology of infection remain broadly overlooked, especially in the Pacific Northwest. The presence of digenean lung flukes has been generally documented in ranid frogs throughout North and South 
America, though comprehensive research is lacking (Bolek \& Janovy, 2007a; Cort, 1915; Dronen, 1977; León-Règagnon, et al., 2001; Whitehouse, 2002). Krull, 1931, demonstrated that infection by lung flukes is limited by the final host's ability to consume the intermediate host; however, it is unknown how infection may change in the definitive host population over time and what morphometrics may be correlated to infection. Infection rates in anuran hosts may also provide indications of ecosystem health because of the complex ecological requirements of the Haematoloechus life cycle.

My study expands on the current breadth of knowledge on this taxon into a previously unstudied area of the United States. The study site, Conboy Lake National Wildlife Refuge (CLNWR), is made up of several permanent waterways and streams amongst the seasonal wet prairie and emergent marsh habitats. The refuge is also habitat for the endangered Oregon spotted frog (Rana pretiosa), which was found to carry Haematoloechus varioplexus in Idaho (Russell \& Wallace, 1992). As indicated in Novak \& Goater (2013), bullfrogs may impact native wildlife through the transmission of non-native parasites as well as altering native parasite dynamics. It is unknown if that is the case at CLNWR, but this assessment of parasite prevalence may provide significant groundwork for future investigation. My study also allows for a temporal examination of parasite prevalence in a population of bullfrogs in southern Washington. Examining the phenological prevalence of infection by adult Haematoloechus sp. and correlations of infection prevalence and intensity to host sex and body size provides information on the species susceptibility to digenean trematodes and general parasite population dynamics. Five years (2013-2016, and 2018) of lung fluke prevalence data and bullfrog morphometric data are used in this study to address the following:

I. The prevalence and intensity of Haematoloechus in bullfrogs at Conboy Lake, Washington.

II. Associations of infection with bullfrog morphometrics and asymmetry of lung infection.

III. Temporal variation of infection and the relationship to bullfrog host diet.

\section{Methods}

Specimen collection and dissection methods were part of, and adapted from, the dissertation work of Dr. Kyle S. Tidwell, "Quantifying the Impacts of a Novel Predator: the 
Distinctive Case of the Oregon Spotted Frog (Rana pretiosa) and the Invasive American Bullfrog (Rana (Aquarana) catesbeiana)", completed in 2017.

Study Area

Conboy Lake National Wildlife Refuge (CLNWR), Washington, USA $\left(45.9581777^{\circ} \mathrm{N}\right.$ $121.3178548^{\circ} \mathrm{W}$ ) was the site of all specimen collection. The refuge complex is comprised of over 6,000 acres of wetlands. Bullfrog collection was predominantly done in water-filled ditch systems running through the refuge, many bordering roadways. CLNWR is one of the few sites in Washington to provide habitat for Oregon Spotted Frogs in co-occurrence with bullfrogs (Hayes, et al., 2001). The refuge supports numerous other species including waterfowl, deer, elk, and trout. The invertebrate species assemblages at CLNWR include more than 25 species of odonates, many of which serve as intermediate hosts to Haematoloechus.

Dominant vegetation in the wetland habitat includes emergent plants such as sedges, rushes, and aquatic plants such as pondweed. Annual snowmelt contributes to streamflow throughout the site as well as annual flooding, however, agricultural modifications have altered hydrology and the scale of flooding in the valley (Henry and Heitmeyer, 2014). Precipitation at CLNWR in November, December, and January is on average greater than $12.7 \mathrm{~cm}$ per month, with low temperatures around -6 degrees Celsius. Summer months experience very little rain $(<2.54 \mathrm{~cm}$ per month) and high temperatures averaging 26 degrees Celsius (Western Regional Climate Center, 2014). Bullfrog activity peaks between July and August, making the period most conducive to collection.

\section{Specimen Collection}

During the summer months of 2013-2018 over 1,900 American bullfrogs were collected from CLNWR. Capture success was greatest during a one month period in 2016 (Figure 2), facilitated by improved capture techniques and environmental conditions. Frogs were predominantly collected at night, by hand-capture, in the wetland complex and ditch system at CNLWR. The focus of collecting effort was on fully metamorphosed frogs, which are most easily detected by eye-shine at night. Headlamps were used to identify bullfrogs in the water and allow capture; additionally, some collection was done through fyke nets, by refuge employees. Fyke nets, mounted cylindrical netting bags, are used in streams and wetland channels at CLNWR primarily for bullhead catfish removal, but bullfrog capture is not uncommon. All frogs 
were euthanized after collection and frozen in bags, marked with collection date and location information.
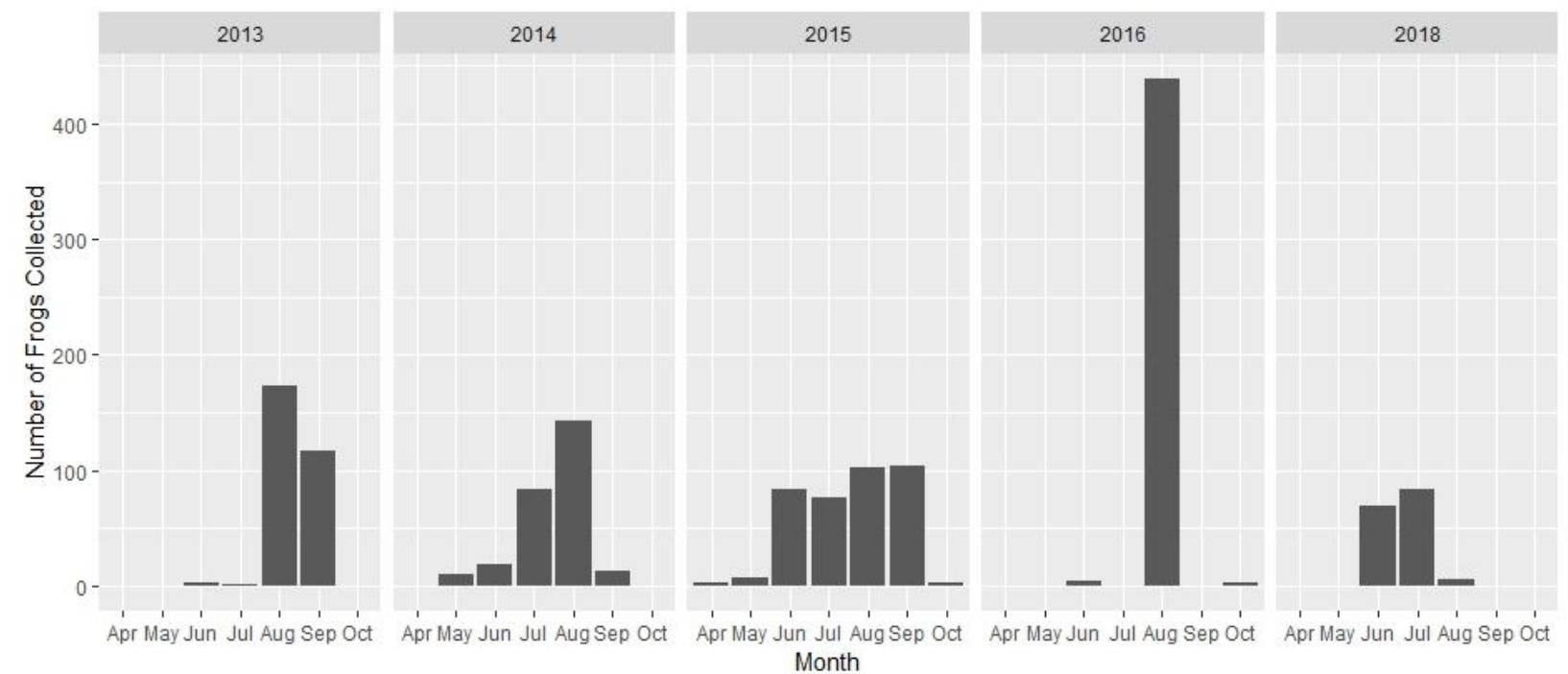

Figure 2. Sampling success shown as the number of frogs collected during each month, across years.

\section{Data Collection}

A total of 1,591 bullfrogs were dissected, with morphometric data and presence of parasites documented for 1,581, and infection intensity (number of flukes) documented for 169 . Frozen specimens were thawed in water prior to dissection and external morphometrics were measured for each specimen prior to internal examination. Lengths were measured with a metric ruler to the nearest 1.0 millimeter. Snout-to-vent length (SVL) was taken by positioning the ventral side of the frog flat against a ruler, tibio-fibular length (shank) by measuring from knee joint to ankle, and gape measured as diameter between commissures (closed mouth). Total body mass and other dietary content mass measurements were taken in grams, using a scientific counting scale (resolution $=0.01 \mathrm{~g}$ ).

Frogs were dissected by cutting the lower abdomen, up to both sides of the neck. For parasite identification the left and right lungs were visually inspected and sometimes removed by cutting each at the base and examined under a dissecting microscope to detect presence or absence of flukes. When documenting intensity of infection in the lungs, each lung was cut open from base to tip and lung flukes were counted and categorized as sexually mature or immature according to Schell (1985).

Sex of the frog was determined by the presence of testes or ovaries and gonadal measurements were taken on the left and right side separately. Length, width, and mass of each 
gonad were measured. Hermaphrodites $(n=20)$ were reported along with a description of external sexual appearance. Fat body mass was measured for left and right sides together. For dietary analysis the stomach was removed by cutting above the cardiac sphincter and below the pyloric sphincter. Stomach volume was taken via water displacement (Magnusson et al., 2003). After dissecting the stomach along the curvature, stomach contents were analyzed using a dissecting microscope. Vegetation and any other non-animal material was not identified or used in analysis. Invertebrate stomach contents were identified to order, while vertebrate contents were identified to species whenever possible. The volume of invertebrate and vertebrate stomach contents were measured via water displacement and stored in $70 \%$ ethanol.

\section{Data Analysis}

Of the total 1,591 frogs dissected, 42 had insufficient data collected, either lacking SVL, gonadal measurements, or lung fluke prevalence. The 1,549 bullfrogs with complete morphometric data were used for the majority of analyses. Frogs were age categorized according to SVL: adults ( $\geq 80 \mathrm{~mm})$, subadults $(60-80 \mathrm{~mm})$, and juveniles (<60mm) (Gahl, et al., 2009). Tadpoles and metamorphosing frogs with Gosner stage $\leq 45$ were not used for analysis in this study (Gosner, 1960). Table 1 shows the distribution of age classes of the 1,580 specimens with SVL recorded; the majority being considered adults. Prevalence of infection was calculated as the number of hosts with flukes divided by the total number examined, and intensity was the number of trematodes per infected host (Lafferty et al., 1997). For the purpose of analysis, fat body mass measurements less than $0.01 \mathrm{~g}$ were considered $0.005 \mathrm{~g}$, and stomach volume less than $0.01 \mathrm{ml}$ was considered $0 \mathrm{ml}$. Gonad lengths less than $0.01 \mathrm{~mm}$ were considered $0.005 \mathrm{~mm}$.

Table 1. Age class distribution of specimens. Number of adult ( $S V L \geq 80$ ), subadult ( $80>$ SVL $\geq 60$ ), and juvenile $(\mathrm{SVL}<60)$ frogs analyzed.

\begin{tabular}{cccc}
\hline & Adult & Subadult & Juvenile \\
\hline Number & 844 & 340 & 397 \\
\hline
\end{tabular}

A binomial logistic regression analysis of infection (infected/not infected) was done using morphometric and temporal predictor variables: sex, SVL, body mass, collection week, month, and year. Hermaphrodites $(n=20)$ represent only $1.3 \%$ of the sample and, therefore, were excluded from the logistic regression model. Pearson's Chi-square test with Yates' continuity correction was used for differences in prevalence between sexes as well as prevalence in odonate 
containing frogs. All statistical analysis was done using R software (v3.5.0; R Development Core Team, 2015) and $P$-values less than 0.05 were considered significant.

\section{Results}

\section{Infection Prevalence}

Overall infection including all age classes was $59.7 \%(n=1580)$. Among adults, overall infection was $90.4 \%$; prevalence in subadults was $43.8 \%$, and juveniles $8.3 \%$. Infection prevalence appeared to be correlated with longer SVL as expected, although not in a linear pattern (Figure 3). Females exhibited a lower infection prevalence than males, at $56.9 \%$ of 768 females and $63.8 \%$ of 756 males. A significant relationship was found between sex and infection $\left(\chi^{2}=7.31, \mathrm{df}=1, P=0.007\right)$. Only 20 specimens were hermaphroditic, 17 of which were adults, with infection prevalence of $80 \%$. Two frogs with an SVL less than 50mm had flukes and both

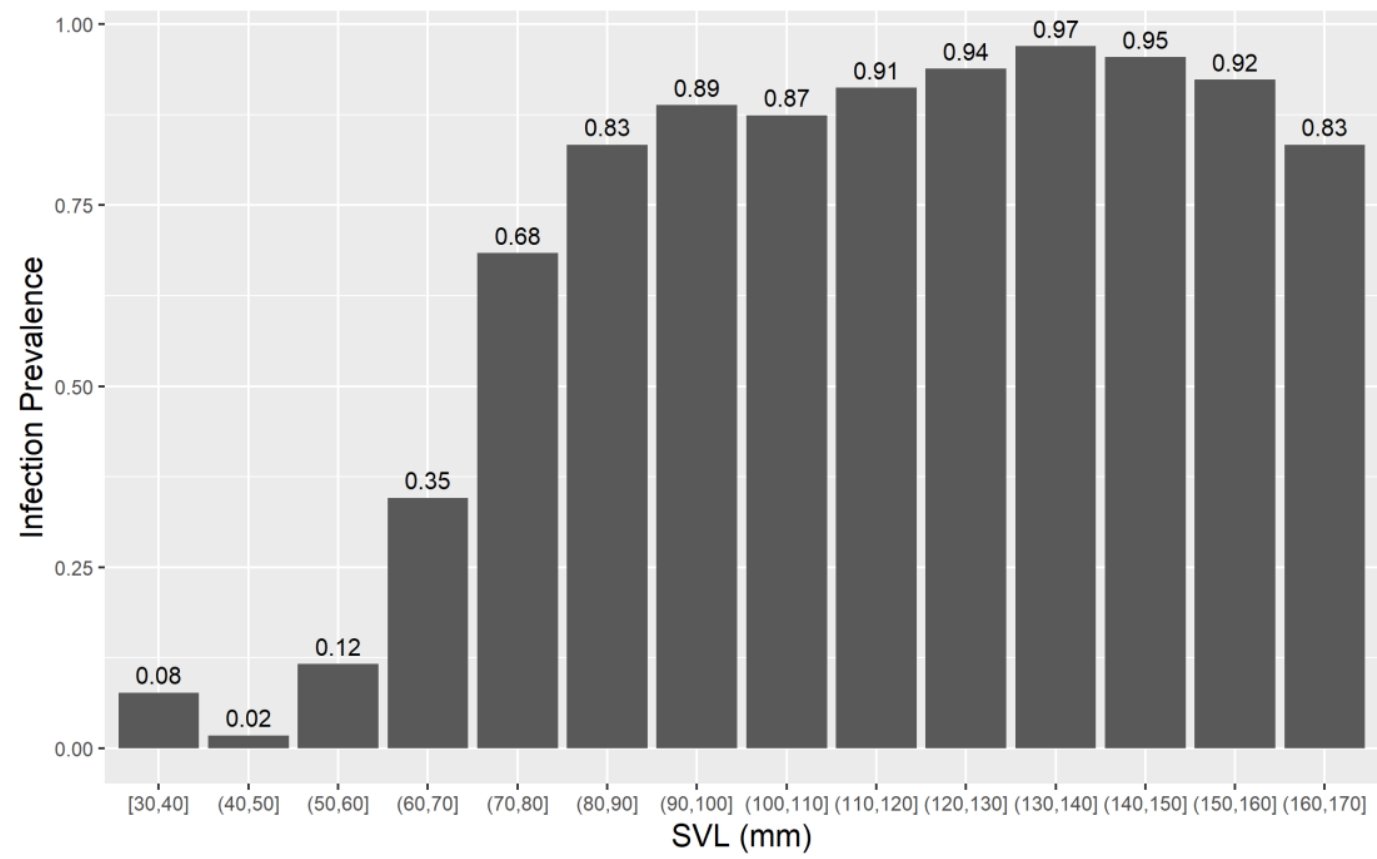

of these specimens were highly degraded, making morphometrics unreliable.

Figure 3. Bar plot of infection prevalence (number of frogs infected divided by total number in the size class) by $10 \mathrm{~mm}$ SVL classes.

The logistic regression model of prevalence demonstrated a positive correlation with host size. The coefficients with standard errors, $P$-values, and odds ratios from the full model are shown in Table 2. Significant predictor variables included SVL, gape, and collection year. A positive relationship between infection and SVL show the odds of expressing flukes increased by 
1.034 for each unit increase in SVL. For each one-unit increase in gape, the odds of infection increased by 1.157 . Collection year was the only significant temporal variable $(\mathrm{OR}=1.117)$, but neither week nor month had a significant relationship to prevalence. The distribution of infection markedly increased accordingly with host size, so infected frogs were more common in higher SVL and gape ranges (Figure 4).

Table 2. Results of binary logistic regression model for infection prevalence with estimated coefficients and standard errors, $P$-values, and odds ratios (OR) with $95 \%$ confidence intervals. Significant variables in bold.

\begin{tabular}{cccc}
\hline Variable & Odds Ratio (95\% C.I.) & Coefficient (S.E.) & $\boldsymbol{P}$-value \\
\hline SVL & $1.034(1.007-1.062)$ & $0.0334(0.013)$ & 0.0123 \\
Gape & $1.157(1.082-1.244)$ & $0.1454(0.036)$ & $<0.001$ \\
Year & $1.117(1.001-1.246)$ & $0.1109(0.056)$ & 0.0464 \\
Mass & $0.995(0.987-0.999)$ & $-5.421 \mathrm{e}-03(3.072 \mathrm{e}-03)$ & 0.0777 \\
Sex & $1.209(0.897-1.630$ & $0.190(3.072 \mathrm{e}-03)$ & 0.2129 \\
Week* & $1.142(0.997-1.308)$ & $0.1327(0.069)$ & 0.0549 \\
Month* & $0.607(0.354-1.038)$ & $-0.4995(0.274)$ & 0.0685
\end{tabular}

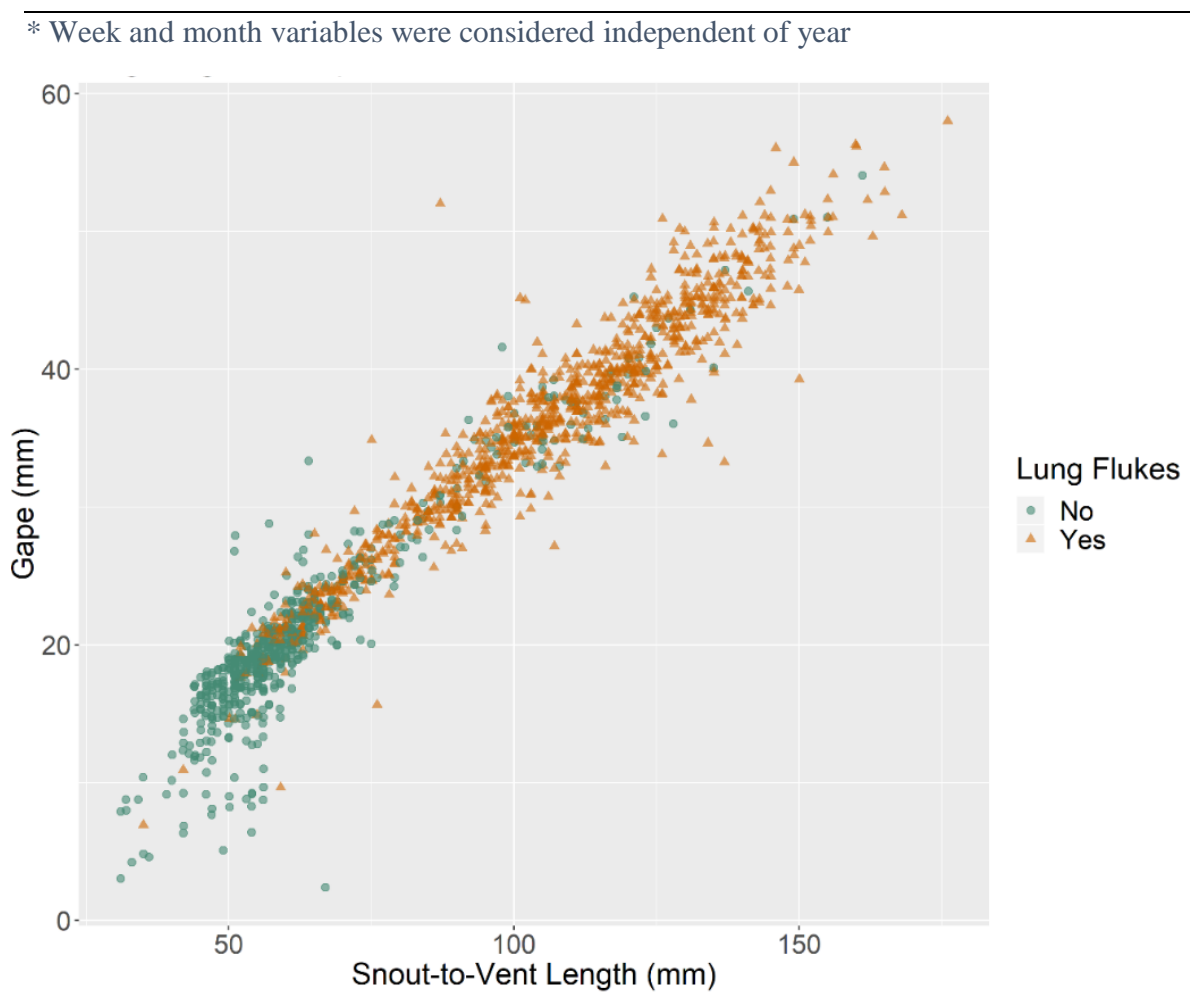

Figure 4. A scatterplot distribution of parasite prevalence by frog SVL $(\mathrm{mm})$ and gape $(\mathrm{mm})$. 


\section{Infection Intensity}

A subset of all sampled frogs were examined for parasite intensity: 140 adults, 25 subadults, and 4 juveniles. Intensity varied considerably, however; the majority of frogs had between 0-20 parasites present, with a mean of 12.6 and median of 6 . Within the intensitymeasured subsample, 18 frogs had visible flukes in the right lung but not the left, and 14 had flukes in the left lung but not the right. Overall, left and right lungs had similar, sharply rightskewed distributions and maximum intensities of 85 and 81, respectively (Figure 5). Both left and right lungs had a median of 3 worms and a mean of 6.3. The highest overall intensity was found in a male bullfrog (SVL $=129 \mathrm{~mm}$, mass $=161.42 \mathrm{~g}$ ), with 166 worms. In another acute case, the mass of 69 total worms in an adult female made up $0.17 \%$ of the frog's total body mass $(112.76 \mathrm{~g})$.

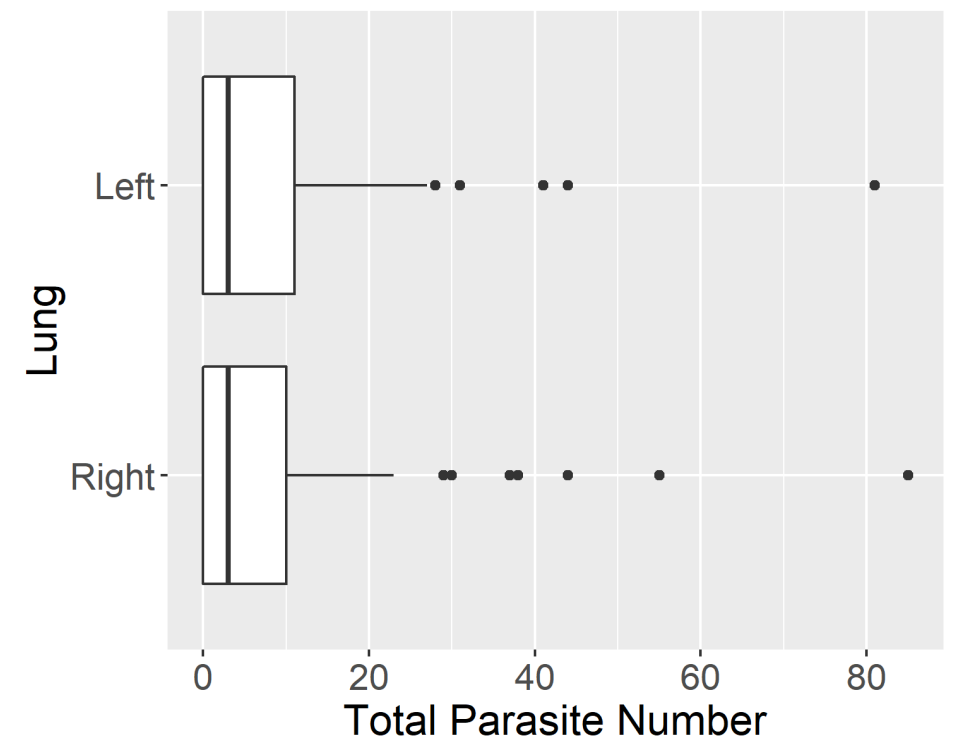

Figure 5. Boxplots of infection intensity (total number of parasites) in the left and right lungs

Intensity appeared to vary by age class, with adults experiencing higher numbers of parasites than either subadults or juveniles. Maximum intensity was 7 worms for juveniles, 32 for subadults, and 166 in adults (Figure 6). While higher intensity was reached with larger body size, no significant correlation was found between SVL and gape with intensity. More variation of intensity occurred with larger host body size, but variation was non-uniform (0-166 SD $\pm 18.2)$. 


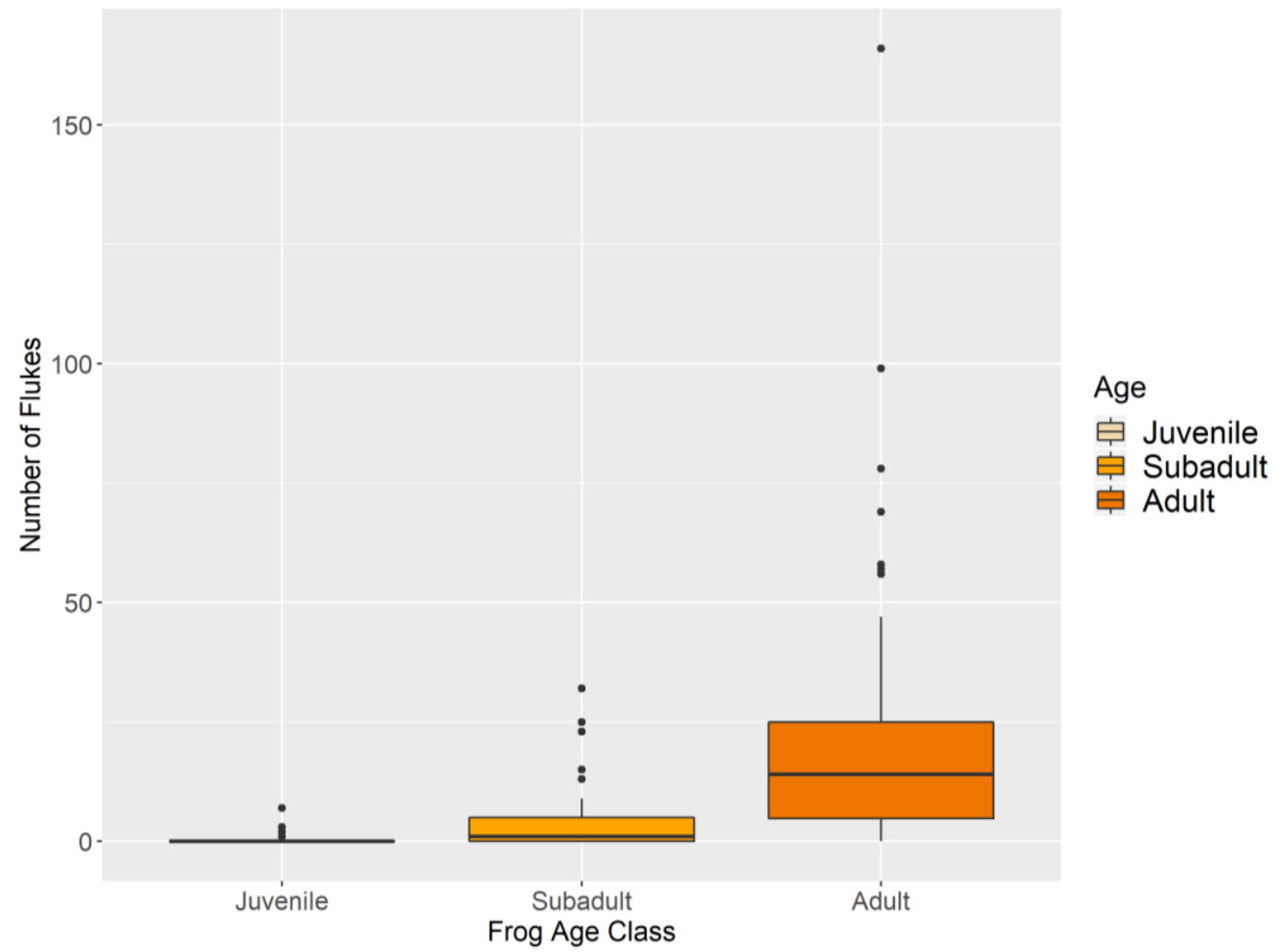

Figure 6. Boxplots of infection intensity (total number of flukes) by frog age class, for a subsample of 169 frogs.

A low proportion of immature parasites were identified, with $75.7 \%$ of counted flukes for all frog age groups classified as mature (Schell, 1985). Subadult frogs, a minority of the subsample, had equal intensities of mature and immature flukes. Adult frogs had a much higher intensity of mature parasites with a total ratio of 7:2.

No relationship was found between gonad size and infection intensity. The mean intensity in gravid females $(n=22)$ was 15.4 , while non-gravid females $(n=73)$ had a mean of 11.2. Sub-sampled males and females also showed no significant differences, with mean intensities of 13 and 12.2, respectively and both with a median of 6. Maximum intensity differed between sexes, with 166 for males and 99 in females.

\section{Infection and Diet}

Odonata comprised over $11.9 \%$ of all invertebrate prey items identified in bullfrog stomachs, with some nymphs potentially having been classified as unknown invertebrate larvae. A significant relationship was found between infection and odonates being identified in bullfrog stomach content, including all frog age classes $\left(\chi^{2}=22.49, \mathrm{df}=1, P<0.001\right) .72 \%$ of all frogs with 
odonates in the stomach carried lung flukes $(n=304)$. Of those frogs with odonate stomach content which did not carry an infection, the majority were subadults and juveniles, only 13 being adults. Frogs with odonate stomach content showed increasing prevalence of flukes, reaching $100 \%$ infection prevalence for all frogs with greater than 7 odonates identified (Figure 7). Fewer than $10 \%$ of juvenile frogs had odonate gut content, compared to $24.4 \%$ of subadults and $22 \%$ of adults.

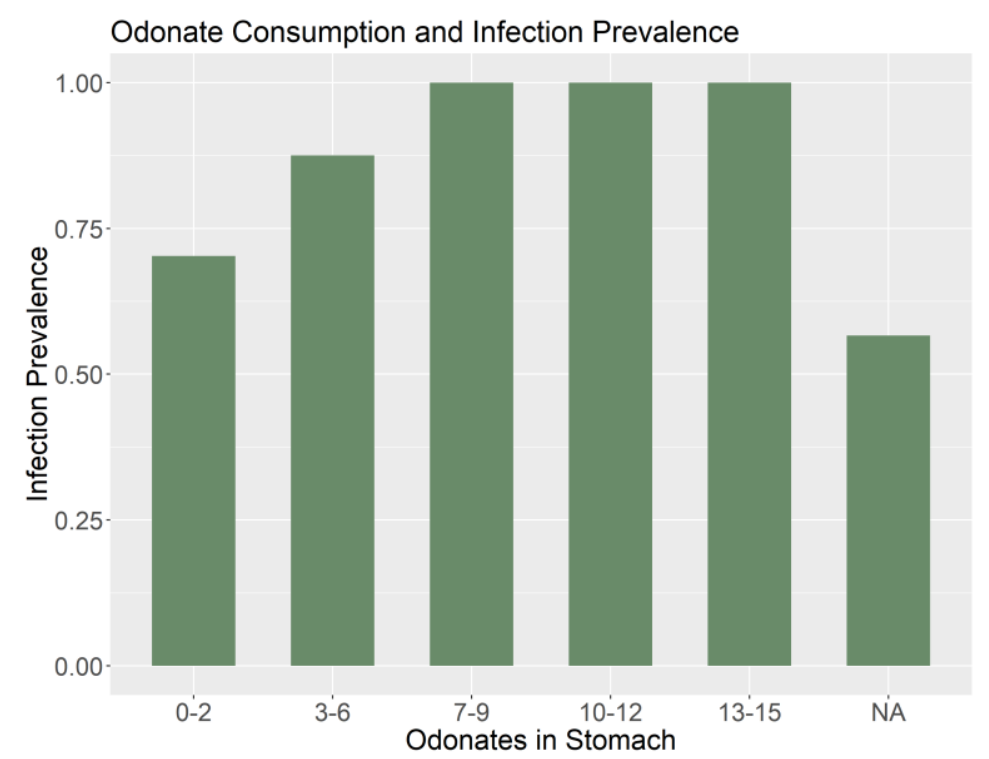

Figure 7. Bar plot of infection prevalence by number of odonates found in the stomach.

Diving beetles (Dytiscidae) made up $31.7 \%$ of invertebrate prey items, by quantity. Other stomach contents included a large variety of both aquatic and terrestrial invertebrates, in addition to unidentifiable arthropods and vertebrate prey.

\section{Discussion}

With five years of infection data, this study represents a long-term description of Haematoloechus in a new geographic region. Lung flukes in CLNWR bullfrogs reflect the highly variable nature of helminth infection, demonstrated in other study sites throughout the United States (Goldberg \& Bursey, 2002; Lank, 1971; McAlpine \& Burt, 1998). Recent studies on lung fluke populations in anurans are extremely limited, however Bolek \& Janovey (2007b) noted a low overall mean intensity of flukes, of approximately 19, in a small sample of bullfrogs from Nebraska, although overall prevalence for their sample was slightly higher at 74\%. In my study, while the majority of bullfrogs collected were found to carry flukes, adults were infected at much 
higher proportions than subadults or juveniles. This imbalance in prevalence and size is likely indicative of diet and gape-limitation restricting smaller frogs' exposure to infection via intermediate host invertebrate prey.

Dronen (2011) found that smaller frogs, or juveniles, could be infected in a lab setting and lack of infection in the wild is likely a consequence of lack of consumption of Odonata. In larger frogs, feeding preferences may contribute to infection differences, or potentially immunological response, or a combination of these factors. Infection rates in odonate hosts are unknown and therefore could be a limitation of frog infection as well. Over half of the bullfrogs in this study were adults. This uneven distribution of age sampling may be a source of some error. Subadult and juvenile groups were still comprised of greater than 300 specimens each, constituting a larger sample size than most previous studies. Dronen (2011) additionally suggests that the metamorphosis of young bullfrogs in the late summer may be coupled with a lack of availability of odonate prey, causing infection to be postponed until the following summer. Shields (1987) identified no effective immune response on the part of the frog in bullfrogs from California, assigning food preference and availability as primary determinants of exposure and infection. Variation of infection prevalence in juveniles exemplifies the multifaceted nature of anuran exposure to the parasite.

The significant relationship between sex and infection was unexpected due to the difference of only $6.9 \%$ in prevalence between males and females, with nearly equal sample sizes. Sex was also not considered a significant predictor of infection in the logistic regression model. The disparity between sexes is, consistent with other several other studies (Hollis, 1972; Less, 1962; Whitehouse, 2002). Breeding season has been found to affect sex differences, potentially due to the influence of hormones within females depressing parasitism (Hollis, 1972; Lees, 1962). Contrary to this hypothesis, prevalence of females at CLNWR appeared high throughout the beginning of sampling periods and even faintly decreased towards the end of the summer. While intensity was largely similar between the sexes, males did display more high intensity outliers, possibly indicating higher susceptibility. The lower intensity in gravid females versus nongravid females also supports the possibility that breeding has an effect on host susceptibility, however, recent research on the topic is lacking.

The logistic model supported the hypothesis that larger frogs are more likely to carry infection, with gape and SVL as significant morphometric predictors and collection year as a 


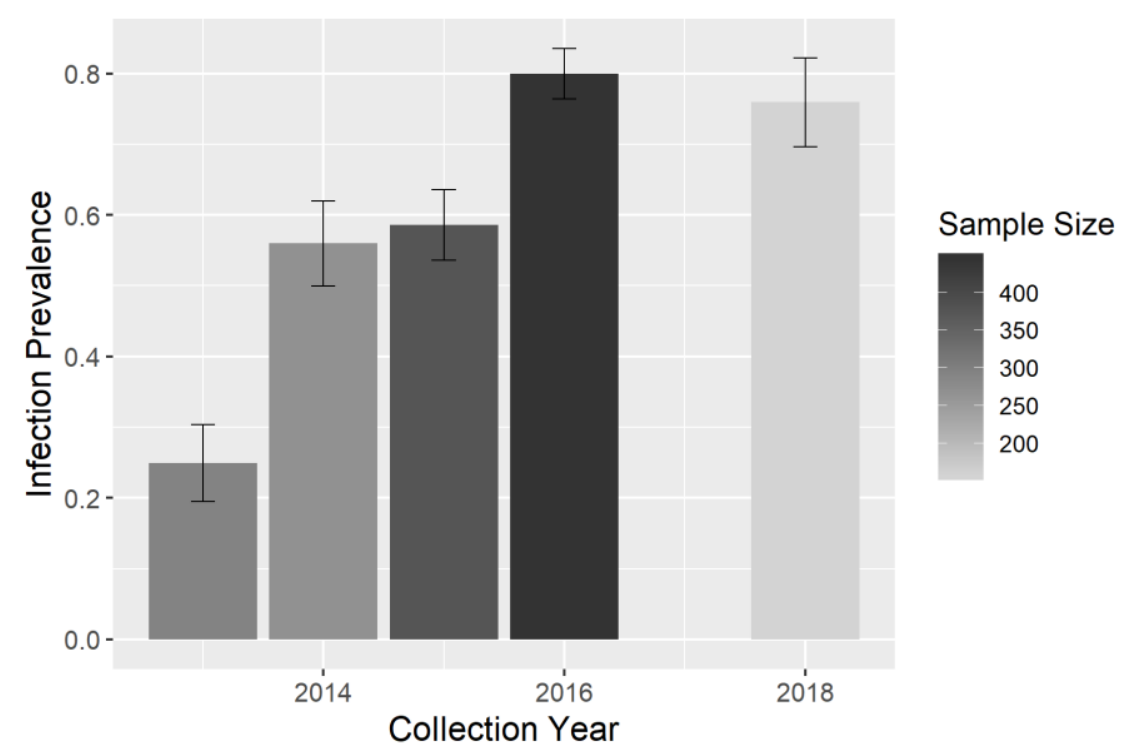

Figure 8. Infection prevalence across collection years (2013-2016, 2018), with 95\% confidence intervals and sample size for each year. Larger sample size is shown in darker shades

temporal predictor (Table 2). Annual fluke prevalence roughly increased across collection years, starting at 25\% $(n=293)$ in 2013 and peaking at 80\% $(n=444)$ in 2016 (Figure 8). Despite this apparent temporal change, heavy sampling in 2016 and overall variation in sampling effort across years (Figure 2, Figure 8) may make collection year unreliable as a predictor. Exclusive summertime collection periods additionally restrict analysis of phenology and no peak infection period was identified within collection months. June and July both had infection prevalence near $70 \%$ across all years, however, August had the heaviest frog sampling $(n=529)$ and overall infection for that month was lower, at $61 \%$.

Seasonal cycles in parasite recruitment are largely dependent on secondary host availability. The specific phenology of Odonata at CLNWR is not well documented, but generally winter months represent periods of very low activity and high mortality for naiads (Lawton, 1971). It is likely that peak activity in odonates, including both naiad activity and adult emergence, corresponds with that of bullfrogs, following overwintering in both organisms. This swell in productivity and consumption in all hosts certainly facilitates transfer of infection across levels of the trophic system and could explain the high levels of infection noted in June and July

Larger gape and SVL appeared to determine much of infection frequency (Figure 4), however, some very large frogs were still found without flukes. Previous research has used mass as an indicator of frog size (Dronen, 1977; Whitehouse, 2002) but the considerable irregularity and fluctuation in frog mass led me to rely on SVL. The lack of infection in some larger frogs 
may be due to strength of immune system, with certain adult frogs serving as less hospitable hosts to flukes (Dare \& Forbes, 2009). Another likely contributor to large frogs lacking flukes is diet preference and the timing of collection. Large frogs may exhibit partiality to certain food types, however, there is extensive agreement that bullfrogs are largely indiscriminate about prey type (Jancowski \& Orchard, 2003; King, et al., 2008). The instantaneous nature of prevalence data allows for the possibility that some frogs had been captured at a time when infection had been recently shed entirely and no new infection been taken on. With few exceptions, bullfrogs with an SVL less than $55 \mathrm{~mm}$ were not found to carry flukes. A transition range in size appears to occur between $60-80 \mathrm{~mm} \mathrm{SVL}$, when frogs recently metamorphosed and the frequency of consumption of larger aquatic invertebrates increases (Jancowski \& Orchard, 2003; Wu et al., 2005).

Across all years, odonate gut content was typically higher towards the beginning of collection seasons and lowest at the end of the summer. Importantly, no distinction was made between nymph and adult Odonata in the dataset. Further analysis on differences in fluke transmission between nymphs and adult odonates is suggested. Additionally, gut content data represents only a snapshot of bullfrog diet, but odonate quantities have been correlated to fluke abundance in previous studies (King, et al., 2008). The seasonal breadth and number of samples collected and analyzed herein represent one of the largest and most comprehensive analyses conducted for the genus Rana and support the notion that when odonates are available during the season bullfrogs will eat them and infection will occur at increasing frequencies with more odonates in the stomach.

While a large proportion of invertebrate prey was Odonata, $31 \%$ was comprised of dytsicid beetles. It is unknown whether dytiscid beetles can carry and transmit flukes to bullfrogs specifically, nonetheless, Bolek and Janovy (2007b) determined water beetles in the family Hydrophilidae can carry $H$. coloradensis. Bullfrogs are, however, considered resistant to $H$. coloradensis, indicating that odonates may be the only source of lung fluke transmission to bullfrogs (Bolek \& Janovy, 2007b; Dronen, 1975). artonate host studies have been restricted to leopard frogs (R. pipiens) and indicate Haematoloechus prevalence is lower in all non-odonate hosts (Bolek \& Janovy, 2007b). Due to the complete absence of studies on Pacific Northwest Haematoloechus, inferences on the potential for non-odonate hosts in the region are ill-founded 
until additional study is done. It should be said that the high odonate diversity at CLNWR likely supports high rates of infection in adult bullfrogs.

Infection intensity had a large range, but the majority of frogs had low numbers of flukes (Figure 6). The connection between SVL and intensity reflects previous studies on bullfrogs and plains leopard frogs (Lithobates blairi) (Dronen, 1978; Goldberg et al., 2000; Shields, 1987). The frogs sampled for intensity were predominantly adults and the lack of smaller frogs in the subsample limits inferences on the exact relationship of size and intensity. A significant correlation between SVL and intensity in plains leopard frogs in the southwestern United States was found by Goldbert, et al. (2000), suggesting larger frogs are able to sustain higher parasite loads. Contrarily, Shields (1987) proposed a combination of diet preference shifts, young frog mortality, and physiological status are the dominant influences on variation of intensity across size classes of frogs. Odonate nymphs are difficult prey items for small frogs since they themselves are predatory and known to feed on frog tadpoles (Hunter et al., 1992). Despite this, bullfrogs feed significantly on odonate nymphs, even more so than adults (B. Frantz, personal observation; Korschgen \& Moyle, 1955). While bullfrogs are known as indiscriminate feeders, preference, or lack thereof, for odonates may be a cause of variation in intensity of adults.

Recruitment of flukes varies with study area, in addition to host species, but most studies show a peak in infection towards the end of summer (Langford et al., 2013; Marin et al., 1998). A model of infection from Marin, et al. (1998) predicted a large increase of recruitment occurring during the early spring, reaching a maximum prevalence of infection during early fall. Langford, et al. (2013) in Nebraska, and Dronen (1987) in New Mexico, indicate a seasonal loss of lung flukes in the early spring and suggest mid-summer as the optimal period for new fluke recruitment. Krull (1931) found that infection is shed early in the summer and new infection taken on throughout the remainder of the active season. In the logistic model (Table 2), neither month nor week were found to significantly predict infection, however, there was very little sampling from the beginning of summer seasons. An even distribution of sampling from spring to fall would likely demonstrate seasonality more conclusively in this region of the United States.

Annual fluctuation was also likely influenced by inconsistent sampling effort. The most productive sampling year was 2016, and prevalence peaked that year as well (Figure 8). Based on Krull's (1931) description of the Haematoloechus life cycle, and Shields' (1987) analysis of 
fluke mortality in bullfrogs, flukes experience senescence and die within a year of being taken on. An experimentally infected frog from Krull (1931) held an infection for a maximum of 15 months. If senescence is the principal cause of mortality in flukes, rather than environmental characteristics or overcrowding effects, death and replacement of flukes in the frog host would occur progressively over the summer. In this case, peak infection would be entirely reliant on the activity of the hosts, rather than variables inherent to the flukes. Changes in annual prevalence may be due in large part to annual rainfall or other environmental factors impacting any of the three hosts. A general trend towards higher infection prevalence over study years is seen in Figure 8. A more detailed examination of annual trends, accounting for the age class of frogs collected each year, is needed to confirm significance in the pattern.

Bullfrogs have been in the Pacific Northwest for around 100 years (Witmer \& Lewis, 2001). Native frogs in the region include Rana pipiens, Rana clamitans and several species of the genus Bufo, all of which carry flukes in other regions of North America (Goldbert \& Bursey, 2002). Novak and Goater (2013) suggest that bullfrogs were the transmission vector of Haematoloechus longiplexus to Vancouver Island, B.C.. The extreme life cycle constraints of Haematoloechus make it very difficult for the parasite to be successful in areas with native fauna which it did not coevolve with. The lack of H. longiplexus historically on Vancouver Island is due to the highly terrestrial nature of the native frogs in the area. Bullfrogs in general have been found to carry heavier helminth loads, due to their highly aquatic nature (McAlpine \& Burt, 1998), and in the case of Haematoloechus, an aquatic ecology is required for infection. Because Washington is habitat for several aquatic and semi-aquatic ranids, introduction of Haematoloechus via bullfrogs is doubtful and native frogs likely held the parasite prior to bullfrog establishment. The presence of $H$. varioplexus in Oregon spotted frogs ( $R$. pretios $a$ ) in Idaho (Russell \& Wallace, 1992) additionally supports Haematoloechus having historically infected ranid frogs in the region and not having been introduced by bullfrogs.

Several limitations are inherent to the logistic model in this study. Chiefly, factors beyond that of collection date and frog morphometrics may be strong determinants in infection. Relevant variables may not have been included or measured, including environmental characteristics over study years. Failure to detect infection was possible, particularly in small, juvenile and subadult, frogs that did not have each lung examined via dissecting microscope. Although flukes are typically conspicuous, this study assumes that if they were not visible with 
the naked eye, they were not present. The extreme variation in infection intensity and prevalence itself in this study indicate that conclusions regarding this parasite should be formed with caution and in consideration of the life cycle as a whole.

The intricacies of Haematoloechus ecology warrant a review of their intermediate hosts. Because no documentation currently exists on Haematoloechus in southern Washington, it is unknown which species serve as primary or secondary host. Several genera of Odonata known to carry infection have been documented at CLNWR, including Libellula, Enallagma, and Ischnura (Bolek \& Janovy, 2007a; Dronen, 1975; Snyder \& Janovy, 1996). There is conflicting evidence as to the intermediate host specificity of different species of Haematoleochus, potentially indicating geographic variation. Novak and Goater (2013) classified H. longiplexus as an intermediate host specialist at Vancouver Island, infecting only Zygoptera (damselflies), while Wetzel and Esch (1996) considered the species a generalist in North Carolina. This specificity reflects how Haematoloechus utilizes the regional diversity in odonate hosts. Information on primary gastropod hosts is additionally inadequate, with Planorbidae and Physidae as the sole snail families described in the U.S. (Bolek \& Janovy, 2007a; Dronen, 1975; Marin, et al., 1998; Novak \& Goater, 2003). Specificity of snail host may follow similar patterns of variation, dependent on the historical geographic range and evolution of the parasite and its hosts. Such factors undoubtedly shape the dynamic interactions of flukes with anurans at CLNWR, and future study would likely unpack the current findings of this work by identifying species specific interactions that explain the variation identified.

Considered in the full context of wetland ecosystem dynamics, Haematoloechus represent the successful ecological relationship amongst various levels of the food web. Predator-prey transactions regulate Haematoloechus survival to reproduction, therefore, future work should investigate each stage of the life cycle within one site. This is especially important in relating the success of the parasite to ecosystem health as a whole. The free-living cercariae of Haematoloechus are exposed to any environmental change affecting water systems. Fluke eggs were found to experience stunted development and infectivity due to high temperatures in New Mexico (Dronen, 1978). Water level changes, eutrophication, acidification, pollution, and weather extremes can affect one or all of the hosts, in addition to cercariae, causing a breakdown in the parasite cycle. CLNWR is a somewhat protected system; additional work should be done to establish if lung fluke abundance differs in sites with varying water quality. Marcogliese \& 
Cone (1977) emphasize that changes in parasite communities can strongly reflect changes in food web function. The evolutionary saga observed through Haematoloechus ' life history is a clear indication of how significant these parasites are in representing trophic connections and ecosystem integrity. 


\section{References}

Bolek, M. G., \& Coggins, J. R. (2003). Helminth community structure of sympatric eastern American toad, Bufo americanus americanus, northern leopard frog, Rana pipiens, and blue-spotted salamander, Ambystoma laterale, from southeastern Wisconsin. Journal of Parasitology, 89(4), 673-681.

Bolek, M. G., \& Janovy Jr, J. (2007a). Evolutionary Avenues For, And Constraints On, The Transmission Of Frog Lung Flukes (Haematoloechus Spp.) In Dragonfly Second Intermediate Hosts. Journal of Parasitology, 93(3), 593-608.

Bolek, M. G., \& Janovy, J. (2007b). Small frogs get their worms first: The role of nonodonate arthropods in the recruitment of Haematoloechus coloradensis and Haematoloechus complexus in newly metamorphosed northern leopard frogs, Rana pipiens, and Woodhouse's toads, Bufo woodhousii. Journal of Parasitology, 93(2), 300-313.

Bolek, M. G., Stigge, H. A., \& Gustafson, K. D. (2016). The iron wheel of parasite life cycles: Then and now!. A Century of Parasitology: Discoveries, ideas and lessons learned by scientists who published in the Journal of Parastiology, 1914-2014, 131-147.

Dronen Jr, N. O. (1975). The Life Cycle of Haematoloechus coloradensis Cort 1915 (Digenea: Plagiorchiidae), with emphasis on host susceptibility to infection. The Journal of parasitology, 657-660.

Dronen, N. O. (1977). Studies on the population structure of two species of Haematoloechus Looss, 1899 (Digenea: Plagiorchiidae) in raniid frogs in New Mexico. Proceedings of the Helminthological Society of Washington, 44, 68-72.

Dronen Jr, N. O. (1978). Host-parasite population dynamics of Haematoloechus coloradensis Cort, 1915 (Digenea: Plagiorchiidae). American Midland Naturalist, 330-349.

Esch, G. W., \& Fernandez, J. C. (1994). Snail-trematode interactions and parasite community dynamics in aquatic systems: A review. American Midland Naturalist, 209-237.

Gahl, M. K., Calhoun, A. J., \& Graves, R. (2009). Facultative use of seasonal pools by American bullfrogs (Rana catesbeiana). Wetlands, 29(2), 697-703.

Goldberg, S. R., Bursey, C. R., \& Platz, J. E. (2000). Helminths of the plains leopard frog, Rana blairi (Ranidae). The Southwestern Naturalist, 45(3), 362-366. 
Goldberg, S. R., \& Bursey, C. R. (2002). Helminths of the bullfrog, Rana catesbeiana (Ranidae), in California with revisions to the California anuran helminth list. Bulletin of the Southern California Academy of Sciences, 101(3), 118-131.

Gosner, K. L. (1960). A simplified table for staging anuran embryos and larvae with notes on identification. Herpetologica, 16(3), 183-190.

Grabda, B. (1960). Life cycle of Haematoloechus similis (Looss, 1899)(TrematodaPlagiorchiidae). Acta Parasitologica Polonica, 8(21/32), 357-367.

Hayes, M. P., Engler, J. D., Van Leuven, S., Friesz, D. C., Quinn, T., \& Pierce, D. J. (2001). Overwintering of the Oregon Spotted Frog (Rana pretiosa) at Conboy Lake National Wildlife Refuge, Klickitat County, Washington, 2000-2001. Interim final report to Washington Department of Transportation by Science Team, Habitat and Wildlife Management Programs, Washington Department of Fish and Wildlife, Olympia, Washington.

Henry, A.R., and Heitmeyer, M.E. (2014). Hydrogeomorphic evaluation of ecosystem restoration and management options for Conboy Lake National Wildlife Refuge. Prepared for U. S. Fish and Wildlife Service, Region 1, Vancouver, WA. Greenbrier Wetland Services Report 14-07.

Hollis, P. D. (1972). Host sex influence on the seasonal incidence of Haematoloechus medioplexus (Trematoda: Plagiorchiidae) in Rana pipiens. Journal of Parasitology, $58(1)$.

Hsu, C. C., Carter, B. D., Williams, D. A., \& Besch-Williford, C. L. (2004). Haematoloechus sp. infection in wild-caught northern leopard frogs (Rana pipiens). Journal of the American Association for Laboratory Animal Science, 43(6), 14-16.

Hunter, M. L., Albright, J., \& Arbuckle, J. (1992). The amphibians and reptiles of Maine. Bulletin (USA).

King, K. C., Gendron, A. D., McLaughlin, J. D., Giroux, I., Brousseau, P., Cyr, D., Ruby, S.M., Fournier, M.\& Marcogliese, D. J. (2008). Short-term seasonal changes in parasite community structure in northern leopard froglets (Rana pipiens) inhabiting agricultural wetlands. Journal of Parasitology, 94(1), 13-23. 
Koprivnikar, J., Marcogliese, D. J., Rohr, J. R., Orlofske, S. A., Raffel, T. R., \& Johnson, P. T. (2012). Macroparasite infections of amphibians: what can they tell us?. EcoHealth, 9(3), 342-360.

Krull, W. H. (1931). Life history studies on two frog lung flukes, Pneumonoeces medioplexus and Pneumobites parviplexus. Transactions of the American Microscopical Society, 50(3), 215-277.

Lafferty, K. D., Shostak, A. W., Bush, A. O., \& Lotz, J. M. (1997). Parasitology meets ecology on its own terms: Margolis et al. revisited.

Langford, G. J., Vhora, M. S., Bolek, M. G., \& Janovy Jr, J. (2013). Co-occurrence of Haematoloechus complexus and Rhabdias joaquinensis in the plains leopard frog from Nebraska. The Journal of parasitology, 99(3), 558-560.

Lank Jr, D. R. (1971). Parasites of the bullfrog in Indiana. In Proceedings of the Indiana Academy of Science(Vol. 81, pp. 359-364).

Lees, E. (1962). The incidence of helminth parasites in a particular frog population. Parasitology, 52(1-2), 95-102.

León-Règagnon, V., Brooks, D. R., \& Zelmer, D. A. (2001). Morphological and molecular description of Haematoloechus meridionalis n. sp. (Digenea: Plagiorchioidea: Haematoloechidae) from Rana vaillanti Brocchi of Guanacaste, Costa Rica. Journal of Parasitology, 87(6), 1423-1427.

Magnusson, W. E., Lima, A. P., Alves da Silva, W., \& Carmozina de Araújo, M. (2003). Use of geometric forms to estimate volume of invertebrates in ecological studies of dietary overlap. Copeia, 2003(1), 13-19.

Marcogliese, D. J., \& Cone, D. K. (1997). Parasite communities as indicators of ecosystem stress. Parassitologia, 39(3), 227-232.

Marcogliese, D. J., King, K. C., Salo, H. M., Fournier, M., Brousseau, P., Spear, P., ... \& Boily, M. (2009). Combined effects of agricultural activity and parasites on biomarkers in the bullfrog, Rana catasbeiana. Aquatic Toxicology, 91(2), 126-134.

Marın, S. L., Grant, W. E., \& Dronen, N. O. (1998). Simulation of population dynamics of the parasite Haematoloechus coloradensis in its three host species: effects of environmental temperature and precipitation. Ecological Modelling, 105(2-3), 185-211. 
Novak, C. W., \& Goater, T. M. (2013). Introduced bullfrogs and their parasites: Haematoloechus longiplexus (Trematoda) exploits diverse damselfly intermediate hosts on Vancouver Island. The Journal of parasitology, 99(1), 59-63.

R Core Team (2015). R: A language and environment for statistical computing. R Foundation for Statistical Computing, Vienna, Austria. URL http://www.R-project.org/.

Russell, K. R., \& Wallace, R. L. (1992). Occurrence of Halipegus occidualis (Digenea: Derogenidae) and other trematodes in Rana pretiosa (Anura: Ranidae) from Idaho, USA. Transactions of the American Microscopical Society, 122-127.

Schell, S. (1985). Handbook of trematodes of North America north of Mexico. Moscow, Idaho: University Press of Idaho.

Shields, J. D. (1987). Pathology and mortality of the lung fluke Haematoloechus longiplexus (Trematoda) in Rana catesbeiana. The Journal of parasitology, 1005-1013.

Snyder, S. D., \& Janovy Jr, J. (1994). Second intermediate host-specificity of Haematoloechus complexus and Haematoloechus medioplexus (Digenea: Haematoloechidae). The Journal of parasitology, 1052-1055.

Tidwell, Kyle Scott, "Quantifying the Impacts of a Novel Predator: the Distinctive Case of the Oregon Spotted Frog (Rana pretiosa) and the Invasive American Bullfrog (Rana (Aquarana) catesbeiana)" (2017). Dissertations and Theses PDXScholar. Paper 3504.

Western Regional Climate Center. Historical data climate summaries. (2014). Desert Research Institute, Reno, Nevada, USA. https://wrcc.dri.edu/Climate/summaries.php, accessed January 2019.

Witmer, G. W., \& Lewis, J. C. (2001). Introduced wildlife of Oregon and Washington. USDA National Wildlife Research Center - Staff Publications

Wu, Z., Li, Y., Wang, Y., \& Adams, M. J. (2005). Diet of introduced Bullfrogs (Rana catesbeiana): predation on and diet overlap with native frogs on Daishan Island, China. Journal of Herpetology, 39(4), 668-675. 